\title{
Dexmethylphenidate Hydrochloride
}

National Cancer Institute

\section{Source}

National Cancer Institute. Dexmethylphenidate Hydrochloride. NCI Thesaurus. Code C47480.

A synthetic sympathomimetic amine with CNS stimulating properties.

Dexmethylphenidate hydrochloride acts by facilitating the release of catecholamines, particularly noradrenaline and dopamine, from nerve terminals in the brain and inhibits their uptake. This leads to an increase in motor activity, causes euphoria, mental alertness and excitement and suppresses appetite. This drug causes dependence and may cause an increase in heart rate and blood pressure. It is used in the treatment of attention deficit hyperactivity disorder. It may also be used in the treatment of fatigue and other nervous system effects seen with chemotherapy. 